\title{
Akt Signals through the Mammalian Target of Rapamycin Pathway to Regulate CNS Myelination
}

\author{
S. Priyadarshini Narayanan, Ana I. Flores, Feng Wang, and Wendy B. Macklin \\ Department of Neurosciences, Lerner Research Institute, Cleveland Clinic, Cleveland, Ohio 44195
}

\begin{abstract}
Mammalian target of rapamycin (mTOR), a well known Akt substrate, regulates multiple cellular functions including cell growth and protein synthesis. The current study identifies a novel role of the Akt/mTOR pathway as a regulator of CNS myelination. Previously, we showed that overexpressing constitutively active Akt in oligodendrocytes in a transgenic mouse model induces enhanced CNS myelination, with no changes in the proliferation or survival of oligodendrocyte progenitor or mature cells. The present study focused on the signaling mechanisms regulating this hypermyelination induced by Akt. Activation of mTOR and its downstream substrates (p70S6 kinase and $\mathrm{S} 6$ ribosomal protein) was observed in Akt-overexpressing oligodendrocytes. When mTOR signaling was inhibited chronically in vivo with rapamycin starting at 6 weeks of age, the observed hypermyelination was reduced to approximately the amount of myelin seen in wild-type mice. mTOR inhibition had little impact on wild-type myelination between 6 and 12 weeks of age, suggesting that, in normal adults, myelination is relatively complete and is no longer regulated by mTOR signaling. However, when mTOR was chronically inhibited in young adult wild-type mice, myelination was reduced. These results suggest that, during active myelination, the major Akt signal regulating CNS myelination is the mTOR pathway.
\end{abstract}

\section{Introduction}

Myelination is a complex developmental process involving the interaction between neurons and glial cells in the CNS. In the CNS, myelin is produced by the differentiation of the oligodendrocyte plasma membrane, and it is essential for normal nervous system development. Oligodendrocyte death and myelin loss are observed in many dysmyelinating and demyelinating diseases, such as multiple sclerosis. We therefore generated transgenic mice that overexpressed constitutively active Akt (Flores et al., 2008), with the intention of generating mice with oligodendrocytes that would survive better in a demyelinating condition. Akt is a serine/threonine kinase that regulates multiple cellular functions by phosphorylating numerous downstream targets in a cellspecific manner. It has been implicated in cell survival, cell proliferation, and cell differentiation in multiple cell systems (Brazil et al., 2004). Unexpectedly, using these transgenic mice that overexpress constitutively active Akt in oligodendrocytes (PlpAkt-DD mice), we found that rather than impacting oligodendrocyte survival, Akt signaling plays an important role in regulating CNS myelination (Flores et al., 2008). Early and enhanced myelination is observed in Plp-Akt-DD brains, with no

\footnotetext{
Received Jan. 15, 2009; revised March 23, 2009; accepted April 13, 2009.

This work was supported by a grant (W.B.M.) and a fellowship (A.I.F.) from the National Multiple Sclerosis Society and National Institutes of Health Grants NS25304 and NS56417 (W.B.M.). We thank Emily Morse and Dr. Grahame Kidd for technical support and Drs. Teresa Wood and William Tyler for valuable discussions and comments on this manuscript.

Correspondence should be addressed to Wendy B. Macklin at her present address: Department of Cell Biology University of Colorado Health Sciences Center, Mail Stop 8108, 12801 East 17th Avenue, P.0. Box 6511, Aurora, C0 80045. E-mail: wendy.macklin@ucdenver.edu.

A. I. Flores's present address: Hospital 12 0ctubre, Unidad de Investigación, Avenida de Córdoba s/n, 28041 Madrid, Spain.

D01:10.1523/JNEUROSCI.0232-09.2009

Copyright $\odot 2009$ Society for Neuroscience $\quad$ 0270-6474/09/296860-11\$15.00/0
}

change in oligodendrocyte number. Thus, although Akt is often considered an important regulator of cell survival, in the developing oligodendrocyte lineage, its overexpression appears to have little impact on oligodendrocyte cell number (Flores et al., 2008). Rather, Akt appears to regulate the amount of myelin generated, producing excess myelin, and this active myelination process continues into adulthood in Plp-Akt-DD mice. At all ages, this hypermyelination is a result of increased myelin production per oligodendrocyte, not increased numbers of oligodendrocytes or their progenitors. In the present study, we focus on the signaling mechanism regulating the Akt-induced hypermyelination observed in Plp-Akt-DD mice.

Specific Akt substrates vary depending on physiological stimulus or cell context (Endersby and Baker, 2008). Mammalian target of rapamycin (mTOR), an important downstream Akt substrate, is a serine/threonine kinase that regulates diverse biological processes important for cell growth, including ribosome biogenesis and protein translation. mTOR activation resulting from phosphatase and tensin homolog deleted on chromosome 10 (PTEN) deficiency in transgenic mice leads to neuronal hypertrophy (Kwon et al., 2003), and significant hyperactivation of mTOR has been reported in numerous human cancers, many of which affect the CNS, including Lhermitte-Duclos disease, tuberous sclerosis complex, and neurofibromatosis type 1 (Sandsmark et al., 2007).

In the current study, we investigated the signal transduction mechanisms by which Akt regulates CNS myelination. We identified mTOR as a major pathway through which Akt signaling regulates CNS myelination. Activation of mTOR and its downstream substrates was observed in Plp-Akt-DD oligodendrocytes, and when mTOR signaling was inhibited in vivo with rapamycin, the enhanced myelination normally seen in Plp-Akt-DD mice 
was reduced. Indeed, when actively myelinating young wild-type (WT) mice were treated with rapamycin, myelin accumulation was reduced. These results suggest that controlled induction of the Akt-mTOR signaling pathway may be a useful target in the development of remyelinating therapies for demyelinating diseases.

\section{Materials and Methods}

Materials. Antibodies were obtained from Abcam $\left[2^{\prime}, 3^{\prime}\right.$-cyclic nucleotide $3^{\prime}$-phosphodiesterase (CNPase), myelin oligodendrocyte glycoprotein (MOG), myelin-associated glycoprotein (MAG), and p-p27KIP1], Millipore Bioscience Research Reagents [myelin basic protein (MBP)], and Cell Signaling Technology [mTOR, phospho-mTOR, p70S6 kinase (p70S6K), phospho-p70S6K, S6 ribosomal protein (S6RP), phosphoS6RP, phospho-glycogen synthase kinase (GSK)-3 $\beta$, phospho-forkhead homolog in rhabdomyosarcoma class O1/class O3a (FOXO1/FOXO3a), and phospho-Bcl-Xl/Bcl-2 associated death promoter (BAD)]. The proteolipid/DM20 protein-specific AA3 clone was originally obtained from Dr. Steven Pfeiffer (University of Connecticut, Farmington, CT) and is grown in this laboratory. Olig2 antibody was a gift from Dr. David Rowitch (Children's Hospital, Boston MA). Rapamycin was obtained from LC Laboratories, and polyethylene glycol (PEG)-400 and Tween 80 were received from Sigma-Aldrich.

Transgenic mice and rapamycin injections. Generation of Plp-Akt-DD mice was described previously (Flores et al., 2008). These mice express constitutively active Akt (Akt-DD) in oligodendrocyte lineage cells.

WT and Plp-Akt-DD mice (6-8 weeks of age or postnatal day 21) were used in rapamycin experiments. Transgenic mice and their littermate controls were divided into rapamycin-injected or vehicle-injected treatment groups. Rapamycin was dissolved in $100 \%$ ethanol and stored at $-20^{\circ} \mathrm{C}$ until use. Immediately before injection, the rapamycin was diluted in vehicle solution to get a final concentration in 5\% PEG-400, 5\% Tween 80 , and $4 \%$ ethanol. Mice received intraperitoneal injections of rapamycin $(10 \mathrm{mg} / \mathrm{kg}$ body weight) or vehicle $5 \mathrm{~d}$ per week for a period of 6 weeks (6-week-old WT or Plp-Akt-DD mice) or 3 weeks [postnatal day 21 (P21) WT mice]. Body weights were recorded weekly. At the end of treatment, mice were either killed for protein or RNA preparation, or perfused and analyzed by immunohistochemistry.

Immunohistochemistry. Perfusion of mice and immunostaining for myelin proteins were performed as described previously (Trapp et al., 1997). Immunohistochemistry for phosphorylated antibodies was done using the protocol of Sgambato et al. (1998), with some modifications. Tris-buffered saline (TBS) containing $100 \mathrm{~nm}$ sodium fluoride (TBSS) was used for all dilutions and washes. On day 1, brain sections $(30 \mu \mathrm{m})$ were prepared with a sliding microtome. Sections were washed three times in TBSS, incubated in $5 \%$ methanol and $3 \% \mathrm{H}_{2} \mathrm{O}_{2}$ for $10 \mathrm{~min}$, washed two times, and then incubated in 10\% Triton X-100 for 20 min. Sections were blocked in $10 \%$ NGS for $1 \mathrm{~h}$. Primary antibodies were diluted in 3\% bovine serum albumin (BSA) containing $0.02 \%$ Triton $\mathrm{X}-100$, and sections were then incubated for $72 \mathrm{~h}$. On day 4 , sections were washed three times in TBSS, followed by overnight incubation in secondary antibodies $(1: 1000)$ at $4^{\circ} \mathrm{C}$. On day 5 , sections were washed three times (10 min each) in TBSS and mounted using Vectashield (Vector Laboratories).

Western blotting. Cerebrum extracts were prepared in $20 \mathrm{~mm}$ MOPS (4-morpholinepropanesulfonic acid)/0.3 M sucrose, $\mathrm{pH} 7.4$, containing $1 \%$ Triton X-100 with protease inhibitor (Roche Diagnostics) and phosphatase inhibitor (Calbiochem) mixtures. Proteins were quantified and analyzed by SDS-PAGE, after which proteins were transferred onto PVDF (polyvinylidene fluoride) membrane and blocked for $1 \mathrm{~h}$ with either $3 \%$ BSA or $5 \%$ milk. Primary antibodies directed against phosphorylated epitopes [p-mTOR(Ser 2448), p-p70S6K(Thr 389), p-S6RP(Ser 235/236), p-GSK-3 $\beta$ (Ser 9), p-FOXO1(Thr 24)/ FOXO3a(Thr 32), p-BAD(Ser 136), and p-p27(Thr187)] were diluted in $3 \%$ BSA, whereas the antibodies directed against nonphosphorylated epitopes [CNPase, MAG, MOG, proteolipid protein (PLP)/DM20, MBP, mTOR, P-70S6K, S6RP, Olig2, and actin] were diluted in 5\% milk, and the blots were incubated overnight at $4^{\circ} \mathrm{C}$. HRP-conjugated secondary antibodies (GE Healthcare) were used at a 1:5000 dilution. Proteins were visualized by chemiluminescence (Thermo Fisher Scientific or GE Healthcare).

Electron microscopy. Mice were perfused with $4 \%$ paraformaldehyde. Optic nerves were dissected and fixed in $4 \%$ paraformaldehyde $/ 2.5 \%$ glutaraldehyde, postfixed in $1 \%$ osmium tetroxide, dehydrated in a graded ethanol series, and Epon embedded. Ultrathin sections $(85 \mathrm{~nm})$ were cut and then stained with uranyl acetate and lead citrate. Electron micrographs were taken on a Philips 201 transmission electron microscope at $60 \mathrm{kV}$.

Calculation of g ratio. $g$ ratios of myelinated fibers were calculated as the ratio of the diameter of the axon to the diameter of the myelinated fiber derived from measuring the respective perimeter using ImageJ software (http://rsb.info.nih.gov/ij/index.html). A minimum of 250 axons per condition was quantified, analyzing samples from three animals per condition.

Quantification of brain section area and corpus callosum area. The area of coronal brain sections (at $0.48 \mathrm{~mm}$ bregma) or of corpus callosum from those same sections was imaged and quantified using Adobe Photoshop. The area of coronal sections from cerebrum was quantified by measuring the area of the hemisphere section using Abode Photoshop and multiplied by 2 to obtain the entire area per section.

RNA extraction and quantitative real-time PCR. Isolation of RNA and real-time PCR were performed as described by Pedraza et al. (2008). Total RNA from WT or Plp-Akt-DD (treated with rapamycin or vehicle) cerebrum tissue was isolated using TRIzol reagent (Invitrogen). cDNA was generated from 1 to $3 \mu \mathrm{g}$ of total RNA by Retrotranscriptase II (Invitrogen) and the transcripts were detected and amplified by quantitative real-time PCR in a LightCycler machine (Roche Diagnostics), following the manufacturer's instructions. Glyceraldehyde 3-phosphatase dehydrogenase (GAPDH) was used as the internal control. All primers were from Sigma-Aldrich (Sigma-Genosys).

Statistical analysis. All statistical analyses were performed using Student's $t$ tests.

\section{Results}

\section{Enhanced myelination in Plp-Akt-DD mice}

Plp-Akt-DD mice exhibit early and enhanced myelination, which continues into adulthood (Flores et al., 2008). Increased expression of the major myelin proteins PLP, DM20, and the MBPs was described in our previous study (Flores et al., 2008), and in this study, we investigated additional critical myelin proteins. As shown in Figure 1, the myelin proteins CNPase and MOG were also elevated in 2-month-old Plp-Akt-DD mice compared with WT mice.

\section{Phosphorylation of FOXO1/O3, GSK3, BAD, and p27 was unchanged in Plp-Akt-DD mice}

Akt and its downstream substrates that regulate cell proliferation, cell survival, cell cycle events, and other cellular functions have been well characterized (Kim et al., 2005). In the present study, we focused on identifying the targets involved in the regulation of Akt-induced hypermyelination of the CNS. A subset of Akt substrates that are involved in regulating apoptosis, gene transcription, or the cell cycle (Fig. $2 \mathrm{~A}$ ) have been shown to impact oligodendrocyte development. For example, GSK- $3 \beta$ has been shown to regulate cell cycle events in oligodendrocyte progenitor cells (Frederick et al., 2007; Yang et al., 2007), and p27kip1, another Akt substrate, also regulates oligodendrocyte development (Casaccia-Bonnefil et al., 1999; Larocque et al., 2005). IGF (insulin-like growth factor) regulates oligodendrocyte progenitor cell survival in optic nerve through Akt signaling and BAD phosphorylation (Pang et al., 2007). Thus, these were all relevant Akt substrates that could potentially regulate the hypermyelination seen in $P l p$-Akt-DD mice, and we therefore investigated whether these signaling partners were involved in the enhanced 

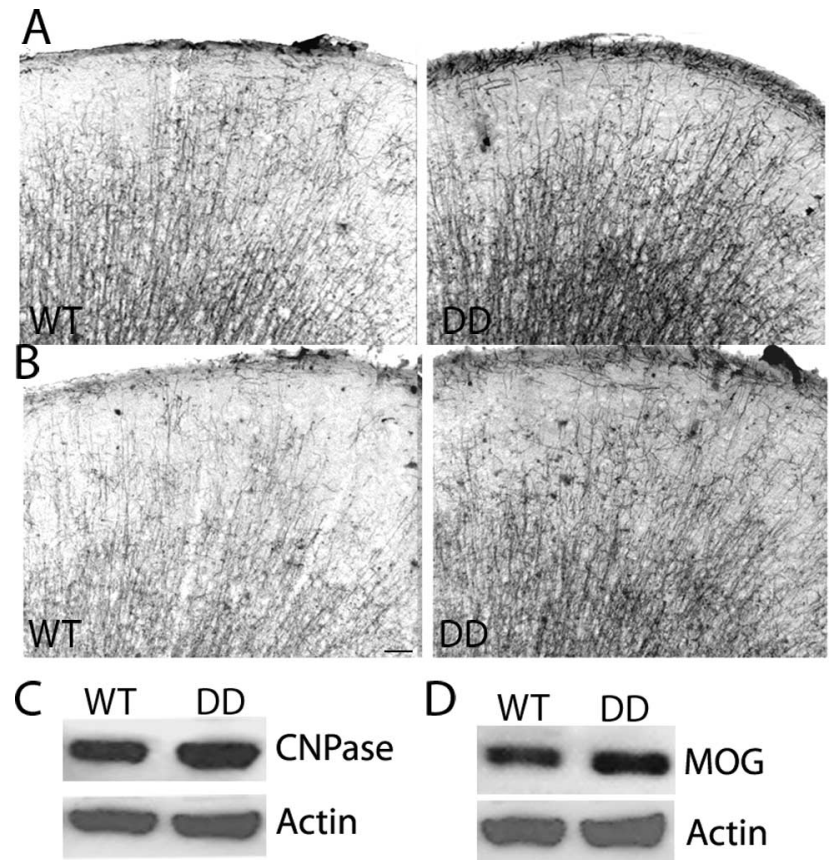

Figure 1. Enhanced myelination in PIp-Akt-DD mice. $A, B$, Coronal sections of cerebrum from 2-month-old WT and Plp-Akt-DD mice stained with antibodies against myelin proteins CNPase $(\boldsymbol{A})$ and MOG $(\boldsymbol{B})$. Note enhanced expression of both myelin proteins in PIp-Akt-DD brain relative to WT brain. A minimum of three animals were analyzed per genotype, and representative images are shown. Scale bar, $100 \mu \mathrm{m}$. C, D, Western blot data showing greater expression of CNPase $(\boldsymbol{C})$ and MOG $(\boldsymbol{D})$ in Plp-Akt-DD mice compared with WT mice at 2 months of age. CNPase expression relative to actin was $1.20 \pm 0.08$ (Plp-Akt-DD) compared with $0.97 \pm 0.04$ (WT); MOG expression relative to actin is $1.01 \pm 0.11$ (PIp-Akt-DD) compared with $0.71 \pm 0.05$ (WT). $N=3$ and $p<0.05$ in both cases.

myelination of our transgenic mouse model. However, Western blot analysis of cerebrum lysates taken from Plp-Akt-DD and WT mice at 2 months of age showed no differences in the phosphorylation of the Akt substrates GSK-3 $\beta$, FOXO1/FOXO3a, p27, or BAD (Fig. $2 B$ ). Similar studies were conducted on WT and PlpAkt-DD mice at P21, the time of active myelination (supplemental Fig. S1, available at www.jneurosci.org as supplemental material), and again no difference was observed in the activation of these Akt substrates. These data indicated that, although these important Akt substrates are phosphorylated in the developing and adult brain, the Akt signaling that regulates enhanced CNS myelination in Plp-Akt-DD mice does not involve these substrates.

\section{Activation of mTOR signaling in Akt- overexpressing oligodendrocytes}

Another major Akt substrate, mTOR, is known to regulate protein translation, with a central role in cell growth regulation (Mamane et al., 2006; Dann et al., 2007). Its upregulation mediates hypertrophy in PTEN-deficient neurons in vivo (Kwon et al., 2003). However, little information is currently available on its role in oligodendrocyte development or myelination. As demonstrated in our previous study (Flores et al., 2008), the enhanced myelination observed in $\mathrm{Plp}$-Akt-DD mice does not result from changes in the number of oligodendrocytes or their progenitors, but rather from increased amounts of myelin generated per oligodendrocyte, which would likely need increased translation of myelin mRNAs. Hence it was reasonable to hypothesize that there was a significant role for mTOR signaling in Akt-induced CNS hypermyelination, and we therefore investigated whether

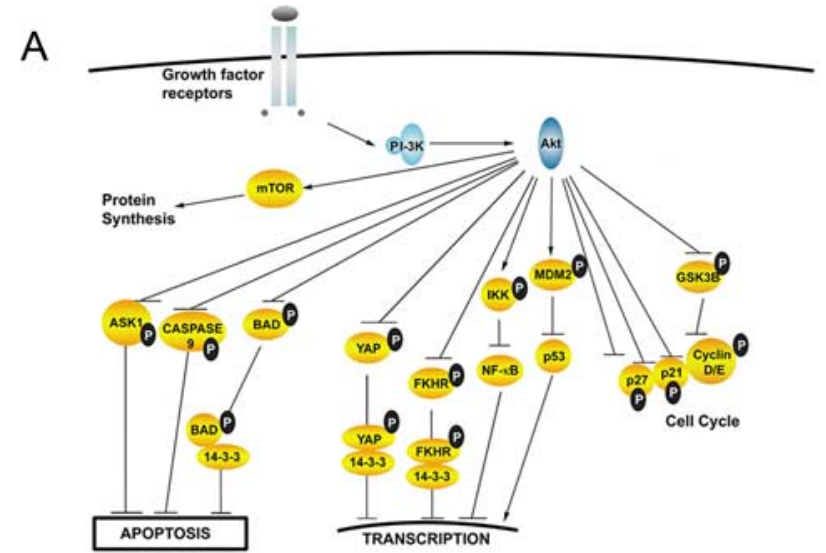

B
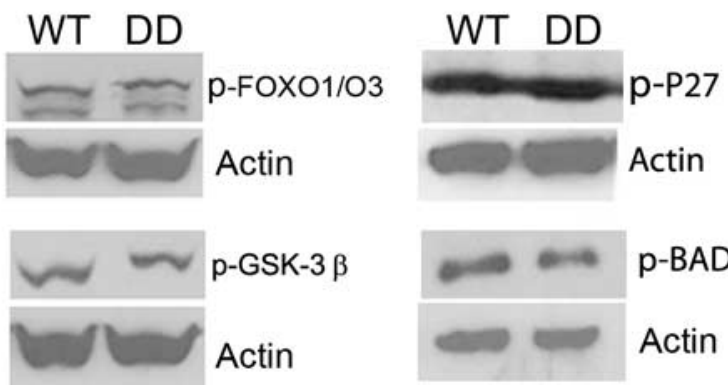

$p-B A D$

Actin

Figure 2. Phosphorylation status of Akt substrates in Plp-Akt-DD brain. $A$, Schematic diagram indicating downstream substrates of Akt that regulate multiple cellular functions. $\boldsymbol{B}$, Western blot analyses of cerebrum lysates from 2-month-old WT and PIp-Akt-DD mice for the Akt substrates GSK-3 $\beta$, F0X01/03, p27, and BAD showed no differences in their phosphorylation status in Plp-Akt-DD samples, relative to WT. A minimum of three animals were analyzed per genotype, and representative blots are shown.

mTOR was activated in Plp-Akt-DD brain. Enhanced phosphorylation of mTOR (Ser 2448) was seen in Plp-Akt-DD brain on Western blot analysis (Fig. 3A). A key downstream mTOR substrate that regulates protein synthesis is the p70 ribosomal protein S6 kinase (p70S6K) (Jastrzebski et al., 2007), with the major substrate of p70S6K being S6RP. We observed enhanced phosphorylation of p70S6K and S6RP in Plp-Akt-DD brain lysates (Fig. $3 A, B$ ). However, the difference was not statistically significant, likely because of the fact that these samples contain multiple cell types (neurons, astrocytes, and microglia) in addition to oligodendrocytes. Given that fact, it was important to demonstrate by immunohistochemistry whether the activation of the mTOR pathway was in Plp-Akt-DD oligodendrocytes. Indeed, enhanced expression of p-mTOR, p-p70S6K, and p-S6RP in oligodendrocytes in the Plp-Akt-DD corpus callosum was observed (Fig. $3 C$ ).

\section{The mTOR inhibitor rapamycin effectively inhibited mTOR signaling in brain}

Although it was evident that the mTOR pathway was activated in Plp-Akt-DD oligodendrocytes, it was unclear whether this was the major signaling pathway regulating the enhanced CNS myelination in this mouse model. To address this question, we inhibited the mTOR pathway in vivo and studied myelination in normal and Plp-Akt-DD mice. Inhibitors of mTOR are being used in cancer therapies (Gridelli et al., 2008) and are proposed for use in several neurologic disorders (Zemke et al., 2007). Inhibition of mTOR signaling by rapamycin is effective in mouse models in vivo (Kwon et al., 2003; Zeng et al., 2008). We therefore 
A

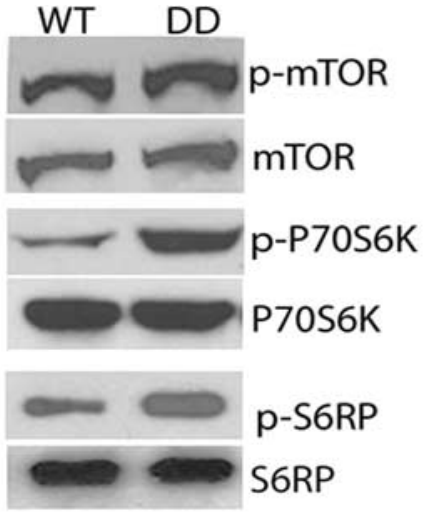

$\mathrm{C}$
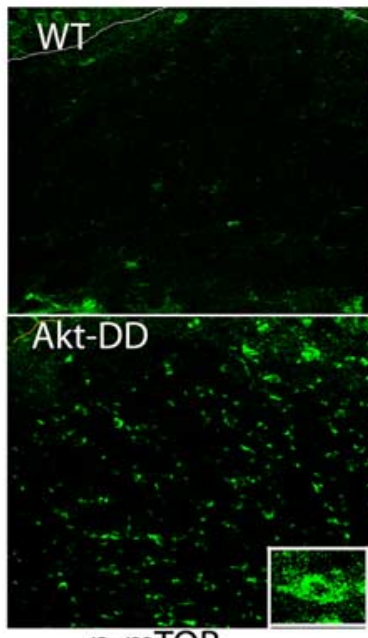

p-mTOR

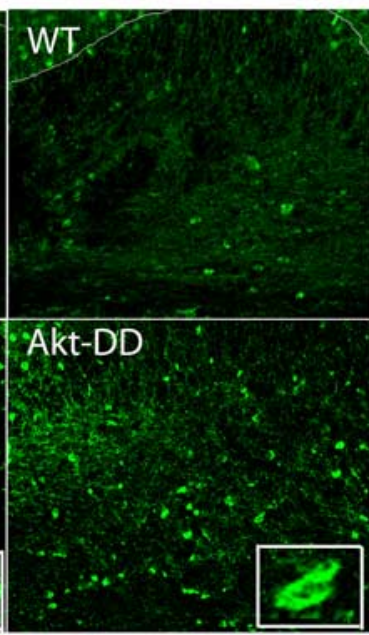

p-P70S6K
B
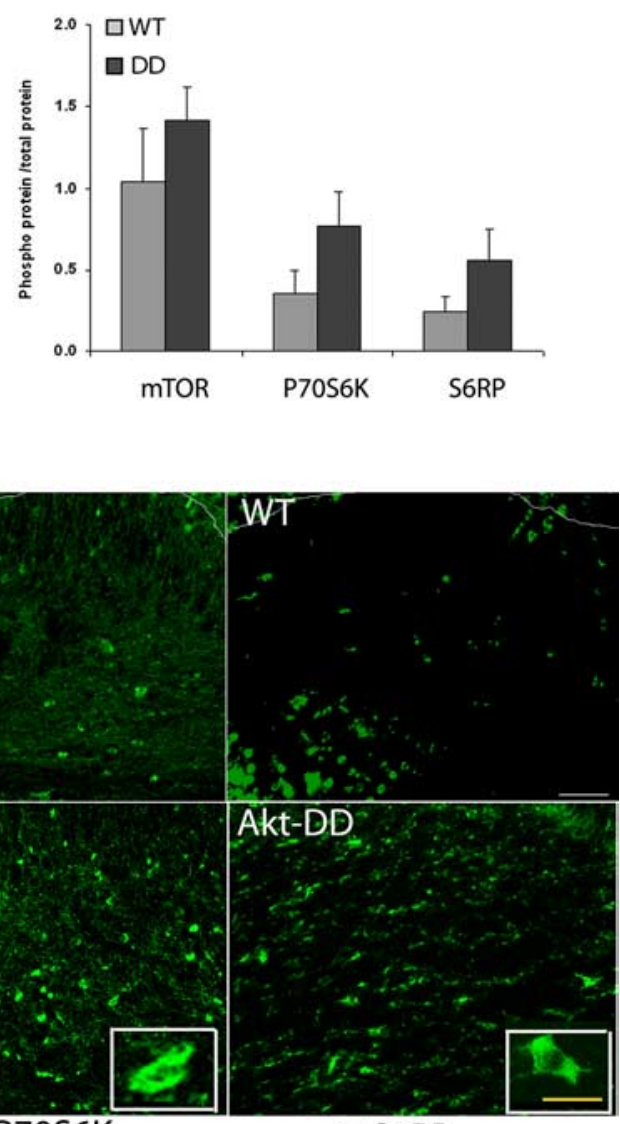

p-S6RP

Figure 3. Activation of the mTOR pathway in PIp-Akt-DD brain. $A$, Representative Western blots showing the activation of mTOR, p70S6K, and S6RP in cerebrum lysates of 2-month-old Plp-Akt-DD samples and WT samples. B, Quantification of the amount of phosphorylated mTOR, p70S6K, and S6RP relative to the expression of their respective total protein levels. Note the increased phosphorylation of these proteins in PIp-Akt-DD mice compared with WT mice. N varies from 3 to 5 . Error bars represent SEM. C, Immunohistochemistry of p-mTOR, p-p70S6K, and p-S6RP in 2-month-old WT and PIp-Akt-DD corpus callosum. Increased expression of these phosphorylated proteins in oligodendrocytes in PIp-Akt-DD corpus callosum confirmed that the activation of mTOR signaling in Plp-Akt-DD samples resulted from increased expression in oligodendrocytes. A minimum of three animals were analyzed per condition, and representative data are shown. The upper edge of the corpus callosum is outlined for WT samples (thin white line), but the corpus callosum fully fills the field in PIp-Akt-DD samples. Scale bar, $50 \mu \mathrm{m}$. The insets show oligodendrocytes immunostained for respective phosphoproteins, taken at high magnification. Scale bar, $20 \mu \mathrm{m}$.

treated adult WT and Plp-Akt-DD littermates (6-8 weeks of age) with rapamycin or vehicle ( $5 \mathrm{~d}$ per week) for 6 weeks. Western blot analysis of brain lysates from rapamycin-treated and vehicletreated animals showed a dramatic reduction in the phosphorylation of S6RP, the downstream substrate of mTOR, in the rapamycin-treated groups of both WT and Plp-Akt-DD mice (Fig. $4 \mathrm{~A}$ ), demonstrating the effective inhibition of the mTOR pathway in vivo after this regimen of rapamycin treatment. No body weight loss was observed in any group at any stage of treatment (supplemental Fig. S2, available at www.jneurosci.org as supplemental material). However, after 6 weeks of treatment, there was a notable decrease in brain size (Fig. $4 B, C$ ) and a significant reduction in the brain weight (Fig. 4D) in both rapamycin-treated WT and Plp-Akt-DD mice, relative to vehicletreated controls. The area of coronal sections of cerebrum was also quantified, and it was significantly reduced in both rapamycin-treated WT and Plp-Akt-DD mice (Fig. $4 E$ ). The reduction in brain section area was slightly greater in the PlpAkt-DD group. Thus, in both WT and Plp-Akt-DD mice, mTOR inhibition reduced brain weight by $\sim 13 \%$ and brain size by $\sim 20 \%$. The exact reason for the reduction in brain size was not studied. However, it is likely that many cells in the nervous system are regulated by mTOR modulation of protein translation. In particular, we noted that the size of neurons in rapamycin-treated WT (supplemental Fig. S3, available at www.jneurosci.org as supplemental material) and Plp-Akt-DD (data not shown) mice was smaller compared with vehicle-treated controls as assessed by NeuN staining, and they appeared more densely packed than in vehicle-treated controls.

\section{Enlargement of corpus callosum was reduced in rapamycin-treated Plp-Akt-DD mice}

We previously showed that the corpus callosum in Plp-Akt-DD transgenic mice is enlarged relative to WT controls (Flores et al., 2008), which is one of the striking features associated with the enhanced CNS myelination in these mice. This difference in the size of the corpus callosum becomes apparent at $\sim 6-8$ weeks of age in PlpAkt-DD mice. In the present study, we analyzed whether the enlargement of the corpus callosum was reversed in Plp-Akt-DD brains after inhibiting the mTOR pathway with rapamycin. To perform a more proficient analysis of the increase in corpus callosum area, and to more accurately observe any changes resulting from rapamycin treatment, $P l p$-Akt-DD/Plp-EGFP and WT/Plp-EGFP littermates with green oligodendrocytes (Mallon et al., 2002; Flores et al., 2008) were studied for better imaging of corpus callosum (Fig. $5 A, B$ ). The corpus callosum area was calculated for WT and Plp-Akt-DD mice treated with vehicle or rapamycin. The enlargement of corpus callosum normally seen in PlpAkt-DD mice was significantly reduced in rapamycin-treated Plp-Akt-DD mice $\left(34.69 \pm 4.86 \times 1000 \mu \mathrm{m}^{2}\right)$ relative to vehicletreated Plp-Akt-DD mice $\left(52.12 \pm 2.99 \times 1000 \mu \mathrm{m}^{2}\right)$, and was comparable with the area of the vehicle-treated WT samples $\left(32.16 \pm 3.69 \times 1000 \mu \mathrm{m}^{2}\right)$ (Fig. $5 C$ ). In the WT group treated with rapamycin, there was a slight reduction in corpus callosum area $\left(30.94 \pm 3.11 \times 1000 \mu \mathrm{m}^{2}\right)$, but this change was not statistically significant.

\section{Myelin $g$ ratios were significantly increased in rapamycin- treated Plp-Akt-DD mice}

Analysis of $g$ ratio is a measure of myelin thickness. Optic nerves from rapamycin-treated or vehicle-treated mice were analyzed by electron microscopy (Fig. 5D,E), and myelin in rapamycintreated $P l p$-Akt-DD optic nerve appeared thinner than in vehicletreated optic nerve, whereas the myelin in the rapamycin-treated or vehicle-treated optic nerves from WT mice seemed unaffected. The $g$ ratios of myelin in electron micrographs of optic nerves from WT and Plp-Akt-DD mice treated with rapamycin or vehi- 

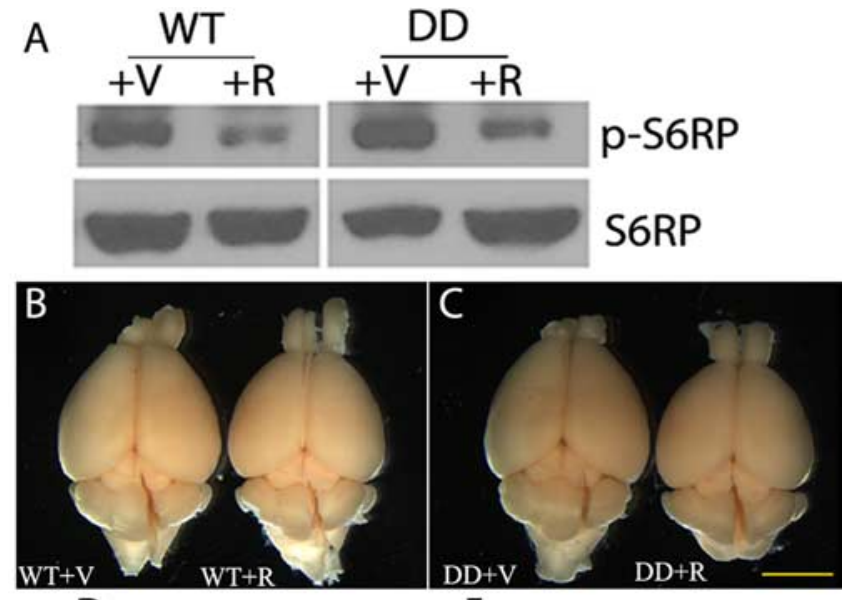

D

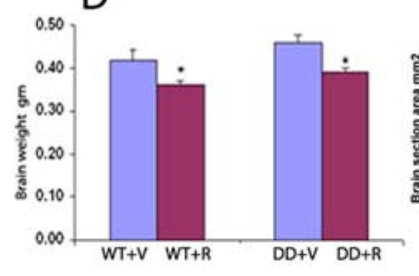

$\mathrm{E}$

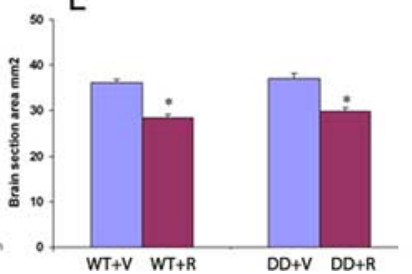

Figure 4. Chronic rapamycin treatment impacted both WT and PIp-Akt-DD brains. Littermate WT and P/p-Akt-DD mice at $6-8$ weeks of age were treated with rapamycin for 6 weeks. $A$, Representative Western blot showing decreased phosphorylation of S6RP in the brain lysates of rapamycin-treated WT and PIp-Akt-DD mice, compared with vehicle-treated WT and PIpAkt-DD mice. $N$ varies from 5 to 7 per condition. $\boldsymbol{B}, \boldsymbol{C}$, Representative images of WT $(\boldsymbol{B})$ and Plp-Akt-DD ( $C$ (12 weeks of age) brains after treatment with vehicle or rapamycin for 6 weeks. Relative to vehicle-treated animals, a reduction in the brain size of rapamycin-treated animals was noted for both WT and PIp-Akt-DD mice. N varies from 9 to 12 per condition. Scale bar, 5 $\mathrm{mm}$. D, Quantification of the reduction in brain weight in rapamycin-treated WT and PIpAkt-DD mice, compared with vehicle-treated animals. Nvaries from 9 to 12 per condition. ${ }^{*} p<$ 0.005 . E, Quantification of the reduction in brain sectional area for both rapamycin-treated WT and Plp-Akt-DD mice. Three consecutive sections from three different animals per condition were used for quantification. ${ }^{*} p<0.005$. Error bars represent SEM.

cle were quantified. In rapamycin-treated Plp-Akt-DD optic nerve, the thickness of myelin was significantly reduced compared with vehicle-treated $P l p$-Akt-DD optic nerve. Thus, the $g$ ratio was significantly higher in rapamycin-treated $P l p$-Akt-DD optic nerve $(0.708 \pm 0.036)$, relative to vehicle-treated $\mathrm{Plp}$ Akt-DD optic nerve $(0.606 \pm 0.026)(p<0.05)$. However, in the WT group, only very minimal change in $g$ ratio was observed. Thus, in the WT group, the $g$ ratio was $0.750 \pm 0.008$ in vehicletreated optic nerve, compared with $0.767 \pm 0.007$ in rapamycintreated WT samples. Scatter plots of the $g$ ratio versus axon diameter $(P l p-A k t-D D$ and WT) highlight the fact that the $g$ ratios were higher in the rapamycin-treated $P l p$-Akt-DD optic nerve, compared with vehicle-treated Plp-Akt-DD optic nerve (Fig. 5G). In WT samples, the scatter plots for vehicle-treated and rapamycin-treated groups overlapped, showing little difference in their $g$ ratios (Fig. $5 F$ ). In all cases, axon diameters remained unaltered. These results confirm the reversal of the enhanced myelination in $\mathrm{Pl} p$-Akt-DD mice on inhibition of the mTOR signaling pathway and suggest that WT samples were relatively unaffected by chronic rapamycin treatment, with respect to myelination.

\section{Changes in the expression of myelin proteins with rapamycin treatment}

As previously shown (Flores et al., 2008) (Fig. 1), the enhanced CNS myelination in $\mathrm{Plp}$-Akt-DD mice is characterized by in- creased expression of myelin proteins relative to WT littermates. Hence it was anticipated that, when the enhanced myelination observed in Plp-Akt-DD mice was reversed by rapamycin treatment, the elevated myelin protein levels would also be reduced in Plp-Akt-DD mice. To study changes in myelin proteins with rapamycin treatment, the expression levels of PLP, DM20, MBP, CNPase, MOG, and MAG were analyzed in rapamycin-treated and vehicle-treated WT and $P l p$-Akt-DD mice. The expression of CNPase, MOG, and MAG in rapamycin-treated $P l p$-Akt-DD mice was significantly reduced compared with vehicle-treated Plp-Akt-DD mice (Fig. 6A,B). This was further confirmed by immunohistochemistry of coronal sections of cerebrum from rapamycin-treated and vehicle-treated $P l p$-Akt-DD mice, and a reduction in immunostaining of CNPase and MOG in the outer cortex of $\mathrm{Plp}$-Akt-DD sections was noted (data not shown). However, in WT mice, the expression of these proteins was only slightly altered when analyzed by both immunoblotting (Fig. 6A) and immunohistochemistry (data not shown). This was consistent with the minimal changes in myelination observed in rapamycin-treated WT animals (Fig. 5).

Although PLP, DM20, and the MBPs are dramatically increased in expression in Plp-Akt-DD brain at all ages, relative to WT brain (Flores et al., 2008), the amounts of these two proteins did not decrease in rapamycin-treated $P l p$-Akt-DD mice (Fig. $6 C$ ), despite that fact that all other measures of myelination in these mice were reduced. This lack of reduction in these proteins was confirmed by immunostaining cerebrum sections for PLP/ DM20 and MBP, which also showed no obvious differences in the expression of these proteins in rapamycin-treated $P l p-A k t-D D$ brains (data not shown). This unexpected series of results could result from at least two different mechanisms. First, it may be that, since these are the two most abundant classes of myelin proteins, their expression is already extremely high by 2 months of age. This is consistent with the observation that the relative increase in these proteins in untreated $P l p$-Akt-DD mice between 6 and 12 weeks is difficult to detect by Western blot (Fig. 6D). Thus, it would be difficult to quantify differences in these proteins within this time frame. Second, it is possible that these two sets of proteins are regulated by a different pathway than the mTOR pathway. This explanation seems less likely, since all myelin mRNAs, including PLP/DM20 and MBP, were significantly downregulated in rapamycin-treated mice relative to vehicletreated Plp-Akt-DD mice (Fig. 6E). Thus, CNP, MOG, and MAG mRNAs and the PLP/MBP mRNAs were expressed at much lower levels in rapamycin-treated $P l p$-Akt-DD brains than vehicletreated brains, and their levels approached those in WT animals. Again, little effect of rapamycin was noted on the expression of any myelin mRNAs in the WT mice (Fig. 6E).

\section{Rapamycin treatment reduced Olig2 expression in Plp-Akt-DD mice}

It was surprising that inhibition of $\mathrm{mTOR}$, which is primarily associated with regulating protein translation, had such a dramatic effect in reducing the level of the myelin mRNAs in $\mathrm{Plp}$ Akt-DD mice (Fig. 6E). We therefore analyzed its impact on regulatory proteins in oligodendrocytes. Olig2 is a major transcription factor that is essential for normal oligodendrocyte specification and differentiation. However, as animals mature, Olig2 protein expression is reduced and it was not detected in adult WT oligodendrocytes (Fig. 7A, top panels). However, as with the myelin proteins, Olig2 protein was upregulated in $P l p$-Akt-DD brains, and after rapamycin treatment, its expression in oligodendrocytes was reduced, as measured by immunohistochemistry 

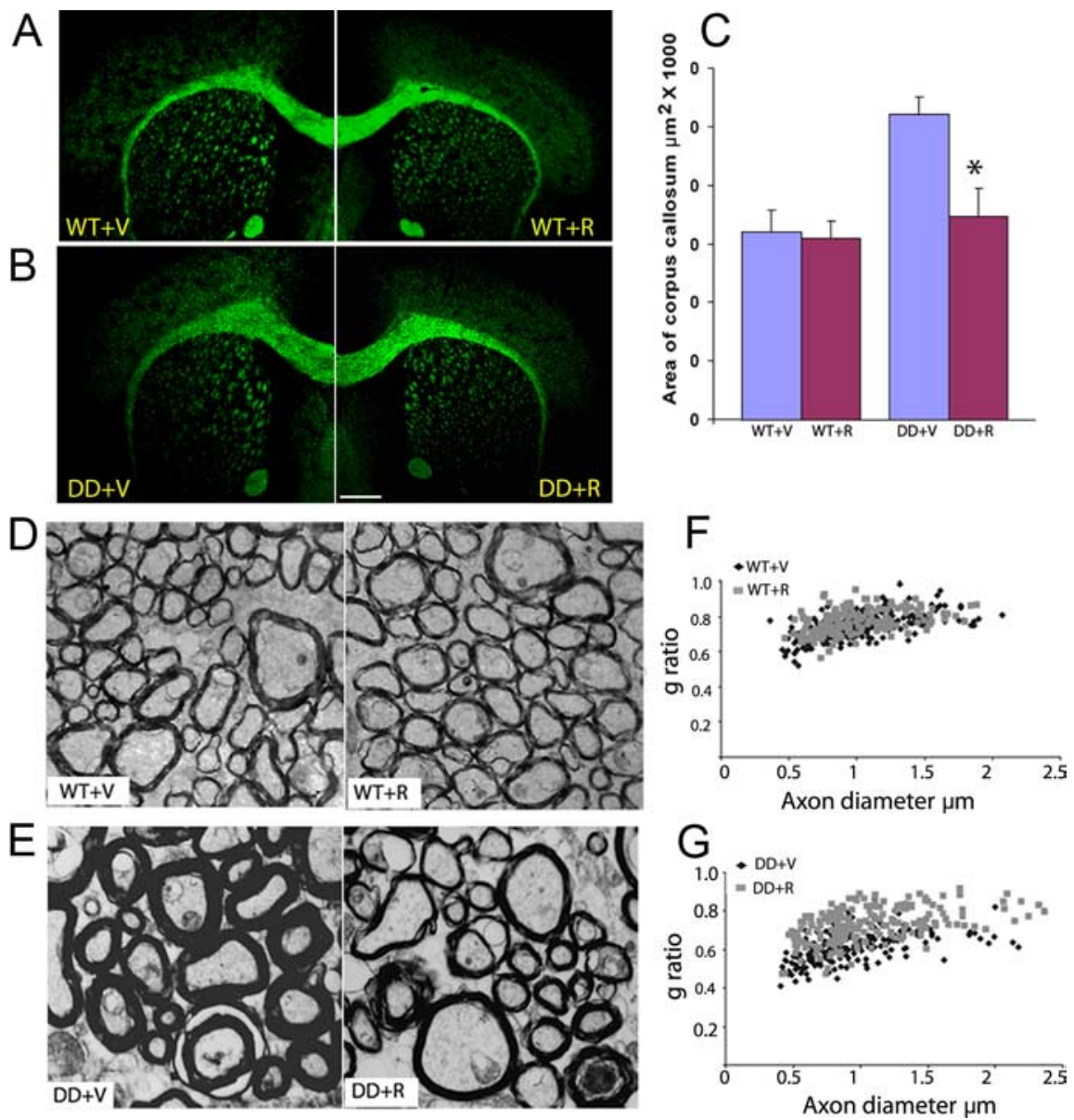

Figure 5. Rapamycin treatment reduced the enhanced myelination in PIp-Akt-DD brains. Littermate WT and PIp-Akt-DD mice at $6-8$ weeks of age were treated with rapamycin for 6 weeks. $A, B$, Confocal images showing the size of the corpus callosum in rapamycin-treated (R) PIp-Akt-DD sections (DD; bottom) or WT sections (WT; top), relative to vehicle-treated sections (V). Scale bar, $500 \mu \mathrm{m}$. C, Quantification of corpus callosum area, showing a significant reduction in rapamycin-treated PIp-Akt-DD animals, compared with the vehicle-treated group. $N=3{ }^{*} p<0.001$. The small reduction in corpus callosum area in the WT group, however, was not significant. $\boldsymbol{D}$, Electron micrograph images of optic nerves from vehicle-treated and rapamycin-treated WT mice, showing no obvious differences in the thickness of myelin after treatment. $N=3$. Magnification, $10,000 \times$. $E$, Electron micrographs of optic nerves from vehicle-treated and rapamycin-treated PIp-Akt-DD mice, showing a reduction of the enhanced myelination after rapamycin treatment. $N=3$. Magnification, $10,000 \times$. $F, G$, Quantification of the $g$ ratios from myelinated axons in the rapamycin-treated and vehicle-treated groups of WT and PIp-Akt-DD optic nerves. In rapamycin-treated PIp-Akt-DD optic nerves, the $g$ ratio was significantly increased, confirming the reduction in myelin thickness. $N=3$; ${ }^{*} p<0.005$. However, there was only a slight increase in the $g$ ratio in rapamycin-treated WT optic nerve, compared with vehicle-treated samples. Error bars represent SEM.

Activation of mTOR is important for myelination in WT oligodendrocytes The current data demonstrate that mTOR and its downstream substrates were not highly activated in WT oligodendrocytes at 2 months of age (Fig. 3) and that inhibition of mTOR signaling with rapamycin had little impact on the amount of myelin or myelin protein/RNA in 12-week-old WT brains (Fig. 6). It seemed unlikely, however, that mTOR had no impact on normal myelination in WT mice. Our previous data indicated that expression of myelin mRNAs continues to increase in WT mice through P21 but then drops off, whereas in $\mathrm{Plp}$-Akt-DD mice, it continues to increase into adulthood (Flores et al., 2008). We therefore analyzed whether mTOR might be expressed at high levels at the time of active myelination in WT oligodendrocytes. WT and Plp-Akt-DD brain sections were analyzed for mTOR and S6RP expression at P21, and phosphorylated mTOR and phosphorylated S6RP were both clearly expressed in oligodendrocytes in the P21 WT corpus callosum (Fig. $8 A, C$ ) as well as in Plp-Akt-DD P21 cells (Fig. $8 B, D$ ). When phosphomTOR expression in WT oligodendrocytes at P21 was compared with that in WT oligodendrocytes at 2 months of age, clearly higher levels of phospho-mTOR were expressed at P21 (supplemental Fig. S4, available at www.jneurosci.org as supplemental material). Thus, it appears that mTOR signaling is elevated in normal oligodendrocytes during active myelination, that it likely impacts active myelination during normal development in WT mice, that it is reduced as normal oligodendrocytes cease active myelination, but that active myelination regulated by $\mathrm{mTOR}$ continues in $\mathrm{Plp}$-Akt-DD mice as they age. In addition to the activation of the mTOR pathway at P21, elevated expression of Olig2 protein was also observed in WT oligodendrocytes at P21 (Fig. 8E), compared with its expression at 3 months of age (Fig.

and Western blot analysis (Fig. 7A,B). These data are important since extensive studies have shown that Olig2 is required for oligodendrocyte production and differentiation, but this is the first report that Olig2 expression remains elevated during active myelination and is downregulated when active myelination ceases. Interestingly, although the Olig2 protein was reduced by rapamycin treatment of $\mathrm{Plp}$-Akt-DD mice, the Olig2 mRNA concentration was not reduced after rapamycin treatment (Fig. 7C). Thus, during active myelination in these hypermyelinating mice, Olig2 continued to be translated and it regulated myelination presumably by regulating myelin gene transcription. Inhibiting the mTOR pathway in $P l p$-Akt-DD mice blocked translation of Olig2 protein, which reduced the overall amount of the myelin mRNAs as well as their proteins, although the Olig2 protein apparently had no impact regulating its own mRNA.
$7 A$, top panels). Intriguingly, the expression of Olig2 per cell appeared increased in $P l p$-Akt-DD oligodendrocytes compared with WT oligodendrocytes at P21 (Fig. 8E, F, note inset images). Thus, at times of active myelination, both in WT oligodendrocytes [P21 (Fig. 8E)] and Plp-Akt-DD oligodendrocytes [P21 (Fig. $8 F$ ); 12 weeks (Fig. 7A)], Olig2 was highly expressed in oligodendrocytes, but it was downregulated as cells shift into a "maintenance" phase in the adult brain.

\section{Inhibition of mTOR signaling in young WT impacted myelination}

To pursue the role of mTOR signaling during normal active myelination, we began studies inhibiting mTOR signaling in younger animals. We noted that, whereas MTOR activity was not high in adult oligodendrocytes (Fig. 3C; supplemental Fig. S4, 
available at www.jneurosci.org as supplemental material), it was quite high in oligodendrocytes at P21 (supplemental Fig. S4, available at www.jneurosci.org as supplemental material). WT mice starting at P21 were therefore treated with rapamycin for 3 weeks and changes in myelination were studied (Fig. 9). The impact of chronic rapamycin treatment on the expression of different myelin proteins and mRNAs in young WT mice was studied by immunohistochemistry, Western blotting, and RNA analysis. The expression of all myelin proteins studied, CNPase, MOG, PLP, DM20 (Fig. 9A), and MBPs (supplemental Fig. S5, available at www. jneurosci.org as supplemental material) was reduced. Although the reduction observed in CNPase and MOG was statistically significant, the decrease in the expression of major myelin proteins PLP, DM20, and MBPs was not statistically significant (Fig. 9B; supplemental Fig. S5B, available at www.jneurosci.org as supplemental material). Immunohistochemistry of coronal brain sections also showed clear reduction in myelin in rapamycin-treated WT mice, when stained by CNPase, PLP/DM20 (Fig. 9C), or MBP (data not shown). Additionally, quantitative analysis of myelin $\mathrm{mR}$ NAs showed reduced levels of all myelin RNAs studied: PLP, MBP, MAG, and CNPase. As with the proteins, the reduction was not statistically significant for PLP and MBP mRNAs (Fig. 9D). These results demonstrate the important role of mTOR signaling during active myelination in normal animals, in addition to its role in modulating hypermyelination induced in Plp-Akt-DD transgenic mice.

\section{Discussion}

Our previous study using this $P l p-A k t-D D$ transgenic mouse model demonstrated a role for Akt activation in CNS myelination (Flores et al., 2008). Akt signaling regulates a variety of cellular functions by mediating extracellular and intracellular signals. More than 30 Akt substrates are implicated in cell survival, growth, differentiation, migration, and metabolism (Kim et al., 2005; Somanath et al., 2006). Akt has been shown to regulate oligodendrocyte progenitor cell cycle (Frederick et al., 2007; Yang et al., 2007) and oligodendrocyte progenitor cell survival (Flores et al., 2000; Pang et al., 2007). However, our studies in Plp-Akt-DD mice demonstrated no significant differences in oligodendrocyte progenitor proliferation or survival, or in the number of mature oligodendrocytes compared with WT (Flores et al., 2008). Thus, the hypermyelination in these mice does not result from changes in the survival or proliferation of oligodendrocyte progenitors or mature cells. This was corroborated with our current observation that many Akt substrates that are particularly involved in cell survival, such as BAD, p27KIP1, GSK-3 $\beta$, and FOXO1/FOXO3, showed no obvious changes in phosphorylation in $\mathrm{Plp}$-Akt-DD mice.
B

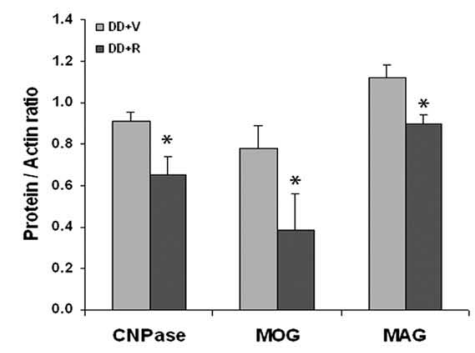

$\mathrm{E}$
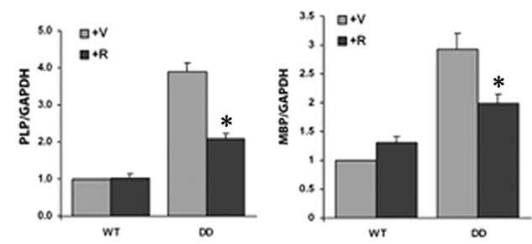

Actin
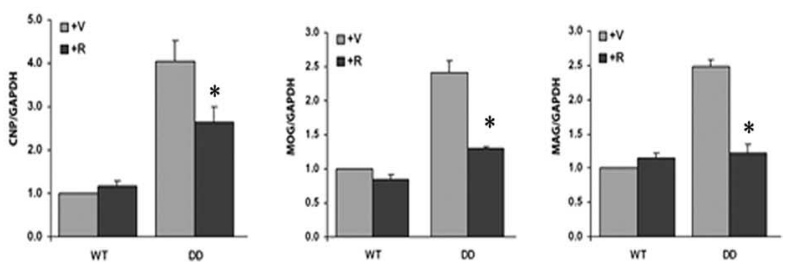

Figure 6. Inhibition of mTOR signaling resulted in changes in the expression of myelin proteins and RNA levels in PIp-Akt-DD brains. Littermate WT and PIp-Akt-DD mice at $6-8$ weeks of age were treated with rapamycin for 6 weeks. $\boldsymbol{A}$, Western blot 年 作 samples for each group. $N=3$. D . Western blot analysis showing that the expression of the major myelin proteins PLP and DM20 does not detectably increase between the ages of 6 and 12 weeks in Plp-Akt-DD mice. $\boldsymbol{E}$, Quantification of myelin RNA levels (CNPase, MOG, MAG, PLP, and MBP) using real-time PCR from the cerebrum samples of rapamycin-treated and vehicle-treated WT and PIp-Akt-DD brains. All myelin RNAs studied were downregulated in rapamycin-treated PIp-Akt-DD samples, compared with samples. Quantification was performed relative to a standard RNA, GAPDH, and then expressed relative to the level of vehicletreated WT sample, which was given an arbitrary value of $1.0 . N=3$ per condition. ${ }^{*} p<0.05$. Error bars represent SEM.

The only Akt substrate that was activated in $P l p$-Akt-DD mice was mTOR. mTOR regulates protein synthesis and cell size in numerous cell types (Ruvinsky et al., 2006). The enhanced myelination in $\mathrm{Pl} p$-Akt-DD mice results from increased myelin gene expression generating increased myelin membrane by Aktoverexpressing oligodendrocytes. Therefore, activation of the mTOR pathway in Plp-Akt-DD oligodendrocytes is consistent with enhanced myelination in these mice. In other studies, mTOR activation occurs in neuronal hypertrophy in PTENdeficient mice because of elevated Akt activity (Kwon et al., 2003), and in increased growth of pancreatic $\beta$-cells expressing constitutively active Aktl (Alliouachene et al., 2008). These data are consistent with mTOR being the primary target of Akt signaling leading to hypermyelination in Plp-Akt-DD mice.

$\mathrm{mTOR}$ can exist in two heteromeric and functionally distinct protein complexes called mTORC1 and mTORC2, based on its 


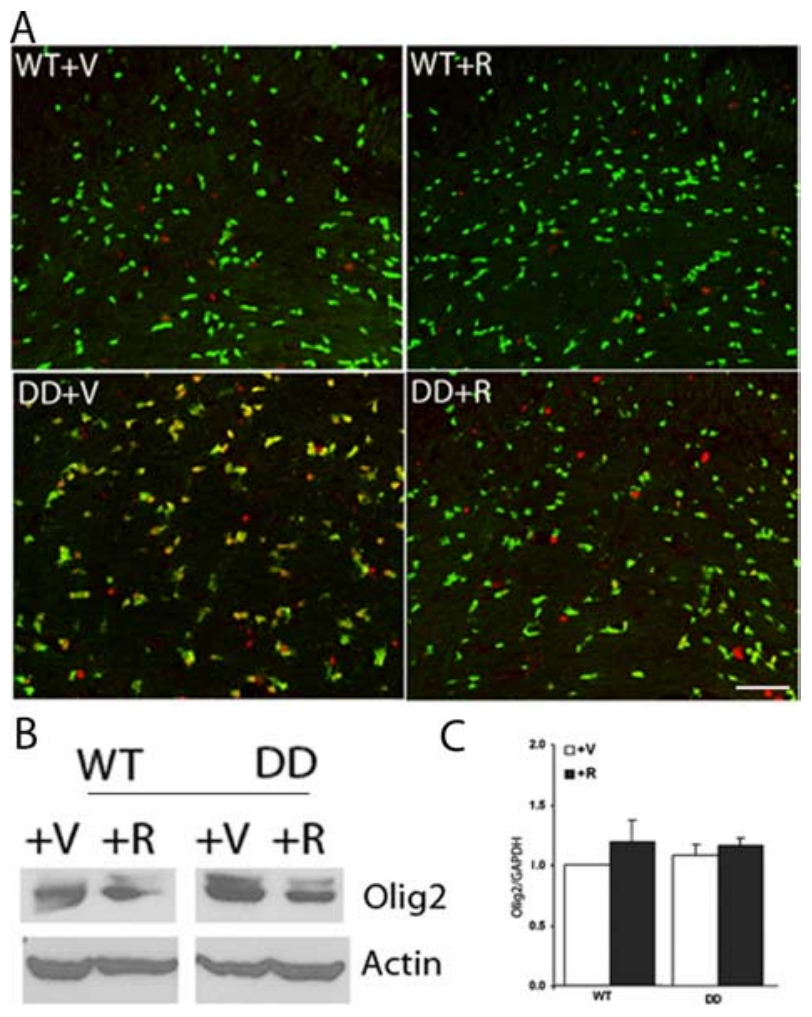

Figure 7. Expression of Olig2 is reduced in rapamycin-treated PIp-Akt-DD brains. Littermate WT and PIp-Akt-DD mice at $6-8$ weeks of age were treated with rapamycin for 6 weeks. $A$, Immunohistochemistry showing 0lig2 expression (red) in the corpus callosum of vehicletreated and rapamycin-treated WT (WT; top) and PIp-Akt-DD (DD; bottom) coronal brain sections. Plp-Akt-DD and WT were crossed with PIp-EGFP mice to optimize visualization of green oligodendrocyte cell bodies. Olig2 expression was noted in Plp-Akt-DD oligodendrocytes but was undetectable in WT oligodendrocytes at this age. Olig2 was downregulated in rapamycintreated Plp-Akt-DD oligodendrocytes. Scale bar, $50 \mu \mathrm{m}$. B. Western blot analysis using cerebrum lysates from vehicle-treated and rapamycin-treated WT and Plp-Akt-DD samples, showing reduced expression of Olig2 in the rapamycin-treated PIp-Akt-DD mice, compared with vehicle-treated PIp-Akt-DD controls. C, Quantitative real-time PCR analysis showing no changes in the expression of Olig2 RNA in rapamycin-treated PIp-Akt-DD or WT compared with vehicletreated controls. Quantification was performed relative to a standard RNA, GAPDH, and then expressed relative to the level of vehicle-treated WT sample, which was given an arbitrary value of 1.0. $N=3$ per condition. Error bars represent SEM.

association with Raptor and Rictor, respectively (Bhaskar and Hay, 2007). mTORC1 regulates numerous cellular processes such as protein translation, autophagy, and microtubule dynamics (Harris and Lawrence, 2003; Swiech et al., 2008), whereas mTORC2 regulates actin cytoskeleton organization, and also regulates Akt activity itself (Jacinto et al., 2004; Sarbassov et al., 2005; Frias et al., 2006; Woo et al., 2007). Regulation of protein translation by $\mathrm{mTORC1}$ involves two independent, cell-specific pathways: activation of ribosomal S6 kinase (S6K) and suppression of the elongation factor 4E-BP-1 (4E binding protein 1) (Ruvinsky and Meyuhas, 2006; Sandsmark et al., 2007; Choo et al., 2008). In our system, activation of mTORC1 and its substrates p70S6K and S6RP was observed in Plp-Akt-DD oligodendrocytes at 2 months of age. Activation of the Akt/mTOR/S6K pathway also occurs in insulinoma formation (Alliouachene et al., 2008), glial cell transformation (Nakamura et al., 2008), vascular malformations (Shirazi et al., 2007), lung carcinoma (Han et al., 2006), and intestinal epithelial cell transformation (Jastrzebski et al., 2007).

Although mTOR signaling has been implicated in many cellular functions in diverse cell types, few studies have focused on a specific role for Akt/mTOR signaling in oligodendrocyte devel-

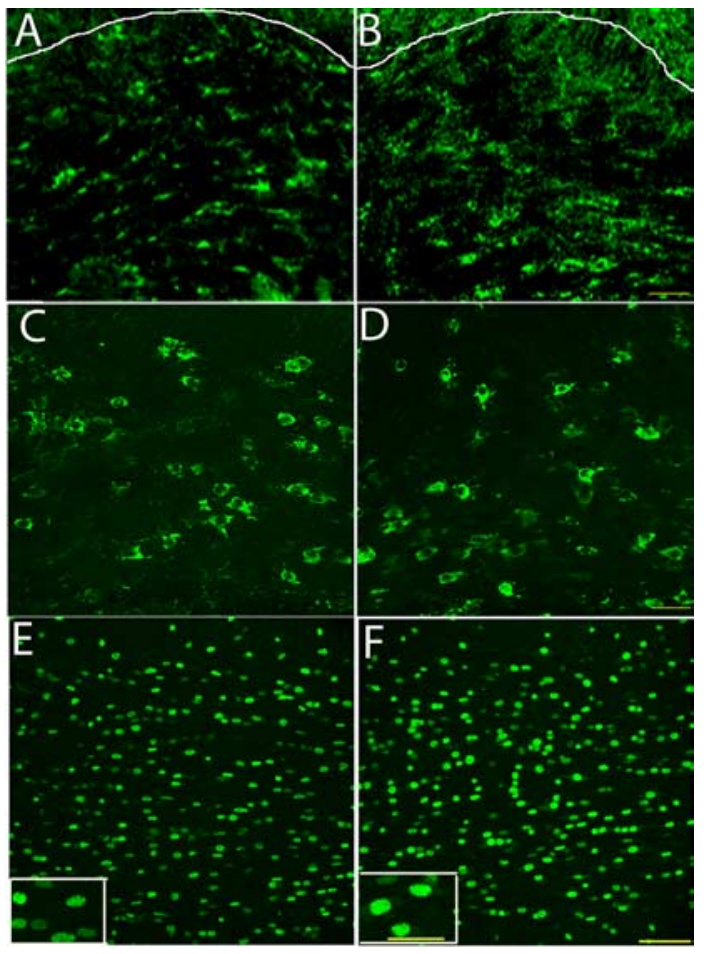

Figure 8. Phospho-mTOR and 0lig2 expression in WT and PIp-Akt-DD brains at P21. $\boldsymbol{A}, \boldsymbol{B}$, Immunohistochemistry of WT $(\boldsymbol{A})$ and Plp-Akt-DD $(\boldsymbol{B})$ corpus callosum analyzing p-mTOR expression showing the activation of $\mathrm{mTOR}$ in WT oligodendrocytes at $P 21$. The upper edge of the corpus callosum is outlined for both WT and PIp-Akt-DD samples (thin white line). The expression of p-mTOR in P21 WT cells appeared comparable with that in P21 PIp-Akt-DD cells. Scale bar, $25 \mu \mathrm{m}$. C, D, Immunohistochemistry showing similar expression levels of p-S6RP in oligodendrocytes of WT $(\boldsymbol{C})$ and Plp-Akt-DD $(\boldsymbol{B})$ at P21, further confirming activation of the mTOR pathway in WT oligodendrocytes during active myelination. Scale bar, $25 \mu \mathrm{m} . \boldsymbol{E}, \boldsymbol{F}$, Expression of Olig2 in corpus callosum of WT (E) and Plp-Akt-DD mice $(\boldsymbol{F})$ at P21. Scale bar, $50 \mu \mathrm{m}$. The Olig2 expression in WT oligodendrocytes was significantly higher at P21 compared with 3 months of age (Fig. 7A). Additionally, the expression level of Olig2 appeared higher in PlpAkt-DD cells at P21 than in P21 WT cells (note inset images; scale bar, $25 \mu \mathrm{m}$ ).

opment. The studies reported here and by Tyler et al. (2009) are the first to establish a role for mTOR in oligodendrocyte differentiation and myelination. Studies in the Wood Laboratory show that the mTOR pathway is essential for the differentiation of oligodendrocyte progenitors (Tyler et al., 2009). In our previous work with this transgenic model, we demonstrated that there is an early enhancement of myelination (Flores et al., 2008). Thus, the overexpression of Akt, and thus mTOR, in these mice leads to early differentiation of oligodendrocytes, consistent with the conclusion that mTOR is essential for oligodendrocyte differentiation. However, there was no change in the number of progenitor cells or mature oligodendrocytes in young or adult animals. Thus, the signals regulating the final number of cells are apparently separate from this Akt/mTOR signaling pathway, and they are limiting. Identifying these signaling pathways is an important future question.

Rapamycin is a specific inhibitor of mTOR, which has been used both in vitro and in vivo to block mTOR function (Dancey 2005). Rapamycin acts primarily through mTORC1, although prolonged rapamycin treatment can also interfere with mTORC2 and affect Akt activity (Sarbassov et al., 2006). Several studies have shown the importance of mTOR as a therapeutic target, and rapamycin and rapamycin analogs [everolimus (RAD001), deforolimus (AP-23573), temsirolimus (CC1-779)] are recommended for cancer therapy as well as in brain injury, brain tu- 
mors, and other neurological disorders (Erlich et al., 2007; Sandsmark et al., 2007; Swiech et al., 2008). Although the rapamycin dosage used in our studies was similar to that in other in vivo animal studies (Kwon et al., 2003; Meikle et al., 2008), it was 15 - to 100 -fold above typical clinical doses (Galanis et al., 2005; Stallone et al., 2005; Pandya et al., 2007), and it was delivered intraperitoneally rather than orally. Nevertheless, it must be noted that, even though these animals exhibited no clinical signs during treatment, significant reduction in brain size and weight in both WT and Plp-Akt-DD rapamycin-treated mice was clearly evident (Fig. 4). This suggests that long-term clinical treatment with rapamycin or other mTOR inhibitors should be undertaken with caution.

When mTOR signaling was inhibited in vivo with rapamycin treatment, the enhanced myelination that is normally seen in $\mathrm{Plp}$-Akt-DD mice was significantly reduced. In contrast, no altered myelination was seen in adult rapamycin-treated WT mice. This would seem inconsistent with the concept that mTOR signaling regulates normal myelination. However, this apparently results from the timing of the rapamycin treatment. Enhanced levels of $\mathrm{p}-\mathrm{mTOR}$ and its substrates were present in WT oligodendrocytes during active myelination at $\mathrm{P} 21$, and when rapamycin treatment was started at $\mathrm{P} 21$, reduction of myelin proteins and mRNAs was seen (Fig. 9). Thus, active myelination was regulated by mTOR in both WT and transgenic mice. In $P l p$-Akt-DD mice, the expression of constitutively active Akt maintained oligodendrocytes in an active myelination state, which was sensitive to rapamycin inhibition, whereas young WT mice had reduced myelin when treated with rapamycin. In contrast, WT mice expressed little p-mTOR in oligodendrocytes as adults (Fig. 3C), when myelination was relatively complete and the amount of myelin was insensitive to mTOR inhibition. Thus, myelin maintenance does not require mTOR activity, whereas active myelination does require it.

The current study appears to contrast with a study showing that rapamycin/ RAD001 treatment of mice with a neuronal model of tuberous sclerosis increased myelination. However, the defective myelination in that model resulted from impaired neuronal signals inducing myelination (Meikle et al., 2007, 2008). In that study, rapamycin was given at early ages and the improvement in neuronal function led to increased myelination. Intriguingly, the myelin in the control mice

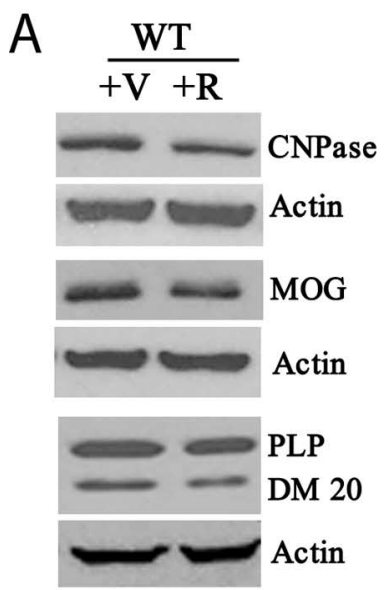

B

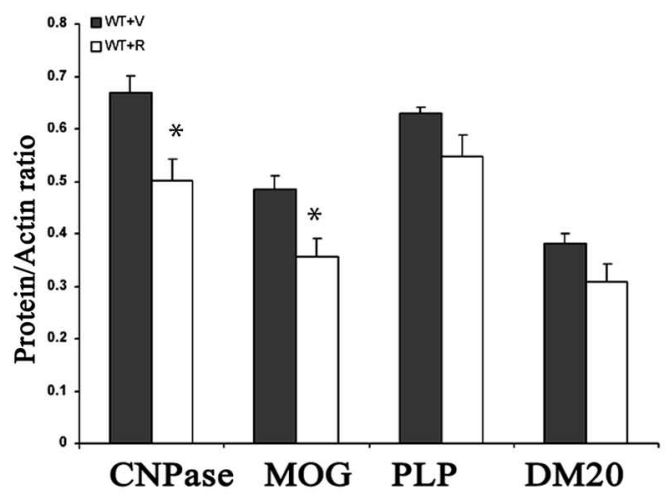

C
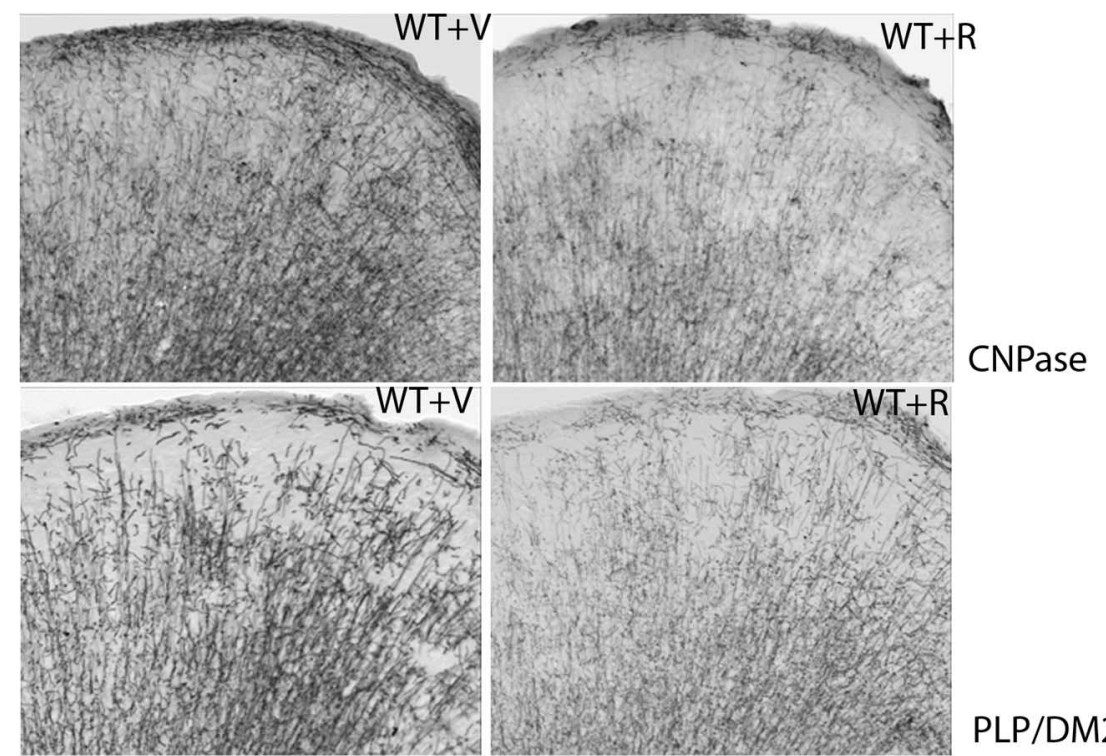

PLP/DM20

D
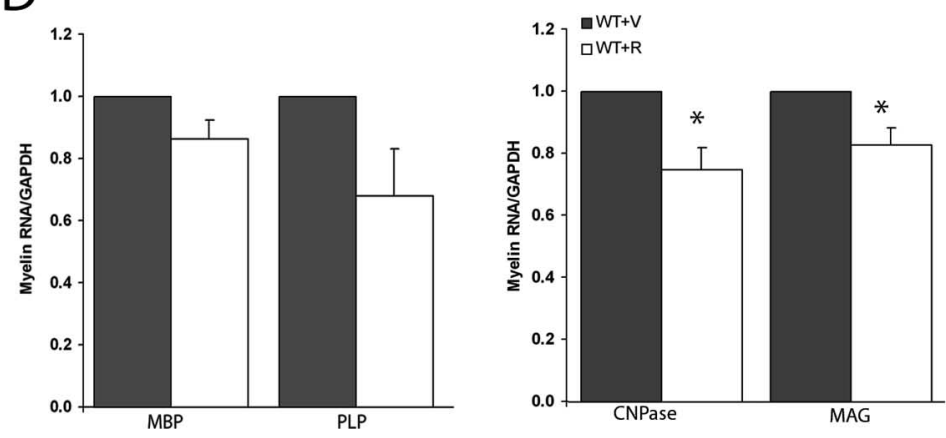

Figure 9. Impact of mTOR inhibition in WT mice during active myelination. $\boldsymbol{A}$, Western blot analysis showing the reduction of myelin proteins (CNPase, MOG, PLP, and DM20) when P21 WT animals were treated with rapamycin $(+R)$ for 3 weeks compared with vehicle-treated controls $(+V)$. $\boldsymbol{B}$, Quantification of Western blots showing the reduction in myelin proteins with rapamycin treatment. The reduction in CNPase and MOG are significant $\left({ }^{*} p<0.05\right)$, whereas the decrease observed in PLP and DM20 was not statistically significant. $N=2$ per genotype. $C$, Immunohistochemistry of coronal brain sections from WT mice treated with vehicle $(+\mathrm{V})$ or rapamycin $(+\mathrm{R})$ demonstrating the reduction of myelinated fibers when stained for CNPase or PLP/DM20.N $=$ 3 per genotype; representative images are shown. Scale bar, $100 \mu \mathrm{m}$. D, Real-time PCR quantification of myelin RNAs in WT animals (P21) treated with vehicle $(+V)$ or rapamycin $(+R)$ for 3 weeks. There is a significant reduction in the expression of CNPase and MAG in the group treated with rapamycin $\left({ }^{*} p<0.05\right)$, whereas the reduction observed in PLP and MBP RNAs was not statistically significant. $N=2$ per genotype. Error bars represent SD. 
treated with rapamycin was clearly reduced relative to control vehicle-treated mice [Meikle et al. (2008), their Fig. 4]. Thus, although this study demonstrates that reducing a neuronal pathology with rapamycin can increase myelination, they clearly show, but do not note, that rapamycin treatment per se reduces myelin in control animals.

It was unexpected that we observed reduction in the increased levels of the minor myelin proteins but could not demonstrate changes in the expression of the abundant myelin proteins PLP, DM20, and the MBPs. This likely resulted from the very high expression of these proteins in brain such that changes over a 6 week time frame could not be detected by Western blotting (Fig. $6 D)$ or immunohistochemistry. This was further supported by our studies on P21 mice treated with rapamycin, in which the reduction of the minor proteins was statistically significant, but not the reduction in PLP and MBP. The possibility does exist that translation of these abundant myelin proteins may be regulated by another signaling pathway. However, it must be noted that rapamycin treatment reduced the significant increases in all myelin mRNAs, including PLP and MBP that are normally seen in Plp-Akt-DD mice (Flores et al., 2008). Considering the central role of mTOR signaling in the translational machinery, the activation of mTORC1 in Plp-Akt-DD oligodendrocytes likely regulates translation of transcription factors that regulate myelin gene transcription. Our study identifies Olig2 as one such molecule. Many studies have shown that Olig2 is essential for oligodendrocyte specification and differentiation (Zhou et al., 2001; Fu et al., 2002; Wang et al., 2006), but very few have focused on its role in myelination via transcriptional regulation of myelin genes per se. Liu et al. (2007) demonstrated that overexpression of Olig2 induced premature oligodendrocyte differentiation by inducing Sox10 and Nkx2.2 expression, thereby increasing myelin gene transcription. Gokhan et al. (2005) demonstrated a direct effect of Olig2 on transcription of the MBP promoter only in conjunction with other transcription factors such as Sox10 and E47. The current in vivo study suggests that Olig2 indeed is a participant in active transcription of myelin genes. Olig2 is normally downregulated in WT cells when they mature, but it remains elevated in actively myelinating cells in Plp-Akt-DD mice until they are prevented from active myelination by rapamycin treatment. Together, the current studies demonstrate that mTOR signaling is essential for active myelination and that, in addition to regulating translation of myelin mRNAs, it may regulate translation of oligodendrocyte transcription factors, thereby regulating myelin mRNA expression itself.

\section{References}

Alliouachene S, Tuttle RL, Boumard S, Lapointe T, Berissi S, Germain S, Jaubert F, Tosh D, Birnbaum MJ, Pende M (2008) Constitutively active Akt1 expression in mouse pancreas requires S6 kinase 1 for insulinoma formation. J Clin Invest 118:3629-3638.

Bhaskar PT, Hay N (2007) The two TORCs and Akt. Dev Cell 12:487-502. Brazil DP, Yang ZZ, Hemmings BA (2004) Advances in protein kinase B signalling: AKTion on multiple fronts. Trends Biochem Sci 29:233-242.

Casaccia-Bonnefil P, Hardy RJ, Teng KK, Levine JM, Koff A, Chao MV (1999) Loss of p27Kip1 function results in increased proliferative capacity of oligodendrocyte progenitors but unaltered timing of differentiation. Development 126:4027-4037.

Choo AY, Yoon SO, Kim SG, Roux PP, Blenis J (2008) Rapamycin differentially inhibits S6Ks and 4E-BP1 to mediate cell-type-specific repression of mRNA translation. Proc Natl Acad Sci U S A 105:17414-17419.

Dancey JE (2005) Inhibitors of the mammalian target of rapamycin. Expert Opin Investig Drugs 14:313-328.

Dann SG, Selvaraj A, Thomas G (2007) mTOR Complex1-S6K1 signaling: at the crossroads of obesity, diabetes and cancer. Trends Mol Med $13: 252-259$
Endersby R, Baker SJ (2008) PTEN signaling in brain: neuropathology and tumorigenesis. Oncogene 27:5416-5430.

Erlich S, Alexandrovich A, Shohami E, Pinkas-Kramarski R (2007) Rapamycin is a neuroprotective treatment for traumatic brain injury. Neurobiol Dis 26:86-93.

Flores AI, Mallon BS, Matsui T, Ogawa W, Rosenzweig A, Okamoto T, Macklin WB (2000) Akt-mediated survival of oligodendrocytes induced by neuregulins. J Neurosci 20:7622-7630.

Flores AI, Narayanan SP, Morse EN, Shick HE, Yin X, Kidd G, Avila RL, Kirschner DA, Macklin WB (2008) Constitutively active Akt induces enhanced myelination in the CNS. J Neurosci 28:7174-7183.

Frederick TJ, Min J, Altieri SC, Mitchell NE, Wood TL (2007) Synergistic induction of cyclin D1 in oligodendrocyte progenitor cells by IGF-I and FGF-2 requires differential stimulation of multiple signaling pathways. Glia 55:1011-1022.

Frias MA, Thoreen CC, Jaffe JD, Schroder W, Sculley T, Carr SA, Sabatini DM (2006) $\mathrm{mSin} 1$ is necessary for Akt/PKB phosphorylation, and its isoforms define three distinct mTORC2s. Curr Biol 16:1865-1870.

Fu H, Qi Y, Tan M, Cai J, Takebayashi H, Nakafuku M, Richardson W, Qiu M (2002) Dual origin of spinal oligodendrocyte progenitors and evidence for the cooperative role of Olig2 and Nkx2.2 in the control of oligodendrocyte differentiation. Development 129:681-693.

Galanis E, Buckner JC, Maurer MJ, Kreisberg JI, Ballman K, Boni J, Peralba JM, Jenkins RB, Dakhil SR, Morton RF, Jaeckle KA, Scheithauer BW, Dancey J, Hidalgo M, Walsh DJ (2005) Phase II trial of temsirolimus (CCI-779) in recurrent glioblastoma multiforme: a North Central Cancer Treatment Group Study. J Clin Oncol 23:5294-5304.

Gokhan S, Marin-Husstege M, Yung SY, Fontanez D, Casaccia-Bonnefil P, Mehler MF (2005) Combinatorial profiles of oligodendrocyte-selective classes of transcriptional regulators differentially modulate myelin basic protein gene expression. J Neurosci 25:8311-8321.

Gridelli C, Rossi A, Maione P (2008) The potential role of histone deacetylase inhibitors in the treatment of non-small-cell lung cancer. Crit Rev Oncol Hematol 68:29-36.

Han S, Khuri FR, Roman J (2006) Fibronectin stimulates non-small cell lung carcinoma cell growth through activation of Akt/mammalian target of rapamycin/S6 kinase and inactivation of LKB1/AMP-activated protein kinase signal pathways. Cancer Res 66:315-323.

Harris TE, Lawrence JC Jr (2003) TOR signaling. Sci STKE 2003:re15.

Jacinto E, Loewith R, Schmidt A, Lin S, Ruegg MA, Hall A, Hall MN (2004) Mammalian TOR complex 2 controls the actin cytoskeleton and is rapamycin insensitive. Nat Cell Biol 6:1122-1128.

Jastrzebski K, Hannan KM, Tchoubrieva EB, Hannan RD, Pearson RB (2007) Coordinate regulation of ribosome biogenesis and function by the ribosomal protein S6 kinase, a key mediator of mTOR function. Growth Factors 25:209-226.

Kim D, Cheng GZ, Lindsley CW, Yang H, Cheng JQ (2005) Targeting the phosphatidylinositol-3 kinase/Akt pathway for the treatment of cancer. Curr Opin Investig Drugs 6:1250-1258.

Kwon CH, Zhu X, Zhang J, Baker SJ (2003) mTor is required for hypertrophy of Pten-deficient neuronal soma in vivo. Proc Natl Acad Sci U S A 100:12923-12928.

Larocque D, Galarneau A, Liu HN, Scott M, Almazan G, Richard S (2005) Protection of p27(Kip1) mRNA by quaking RNA binding proteins promotes oligodendrocyte differentiation. Nat Neurosci 8:27-33.

Liu Z, Hu X, Cai J, Liu B, Peng X, Wegner M, Qiu M (2007) Induction of oligodendrocyte differentiation by Olig2 and Sox10: evidence for reciprocal interactions and dosage-dependent mechanisms. Dev Biol 302:683-693.

Mallon BS, Shick HE, Kidd GJ, Macklin WB (2002) Proteolipid promoter activity distinguishes two populations of NG2-positive cells throughout neonatal cortical development. J Neurosci 22:876-885.

Mamane Y, Petroulakis E, LeBacquer O, Sonenberg N (2006) mTOR, translation initiation and cancer. Oncogene 25:6416-6422.

Meikle L, Talos DM, Onda H, Pollizzi K, Rotenberg A, Sahin M, Jensen FE, Kwiatkowski DJ (2007) A mouse model of tuberous sclerosis: neuronal loss of Tsc1 causes dysplastic and ectopic neurons, reduced myelination, seizure activity, and limited survival. J Neurosci 27:5546-5558.

Meikle L, Pollizzi K, Egnor A, Kramvis I, Lane H, Sahin M, Kwiatkowski DJ (2008) Response of a neuronal model of tuberous sclerosis to mammalian target of rapamycin (mTOR) inhibitors: effects on mTORC1 and Akt 
signaling lead to improved survival and function. J Neurosci 28:5422-5432.

Nakamura JL, Garcia E, Pieper RO (2008) S6K1 plays a key role in glial transformation. Cancer Res 68:6516-6523.

Pandya KJ, Dahlberg S, Hidalgo M, Cohen RB, Lee MW, Schiller JH, Johnson DH (2007) A randomized, phase II trial of two dose levels of temsirolimus (CCI-779) in patients with extensive-stage small-cell lung cancer who have responding or stable disease after induction chemotherapy: a trial of the Eastern Cooperative Oncology Group (E1500). J Thorac Oncol 2:1036-1041.

Pang Y, Zheng B, Fan LW, Rhodes PG, Cai Z (2007) IGF-1 protects oligodendrocyte progenitors against TNFalpha-induced damage by activation of PI3K/Akt and interruption of the mitochondrial apoptotic pathway. Glia 55:1099-1107.

Pedraza CE, Monk R, Lei J, Hao Q, Macklin WB (2008) Production, characterization, and efficient transfection of highly pure oligodendrocyte precursor cultures from mouse embryonic neural progenitors. Glia 56:1339-1352.

Ruvinsky I, Meyuhas O (2006) Ribosomal protein S6 phosphorylation: from protein synthesis to cell size. Trends Biochem Sci 31:342-348.

Sandsmark DK, Pelletier C, Weber JD, Gutmann DH (2007) Mammalian target of rapamycin: master regulator of cell growth in the nervous system. Histol Histopathol 22:895-903.

Sarbassov DD, Guertin DA, Ali SM, Sabatini DM (2005) Phosphorylation and regulation of $\mathrm{Akt} / \mathrm{PKB}$ by the rictor-mTOR complex. Science 307:1098-1101.

Sarbassov DD, Ali SM, Sengupta S, Sheen JH, Hsu PP, Bagley AF, Markhard AL, Sabatini DM (2006) Prolonged rapamycin treatment inhibits mTORC2 assembly and Akt/PKB. Mol Cell 22:159-168.

Sgambato V, Vanhoutte P, Pages C, Rogard M, Hipskind R, Besson MJ, Caboche J (1998) In vivo expression and regulation of Elk-1, a target of the extracellular-regulated kinase signaling pathway, in the adult rat brain. J Neurosci 18:214-226.

Shirazi F, Cohen C, Fried L, Arbiser JL (2007) Mammalian target of rapamycin (mTOR) is activated in cutaneous vascular malformations in vivo. Lymphat Res Biol 5:233-236.
Somanath PR, Razorenova OV, Chen J, Byzova TV (2006) Akt1 in endothelial cell and angiogenesis. Cell Cycle 5:512-518.

Stallone G, Schena A, Infante B, Di PS, Loverre A, Maggio G, Ranieri E, Gesualdo L, Schena FP, Grandaliano G (2005) Sirolimus for Kaposi's sarcoma in renal-transplant recipients. N Engl J Med 352:1317-1323.

Swiech L, Perycz M, Malik A, Jaworski J (2008) Role of mTOR in physiology and pathology of the nervous system. Biochim Biophys Acta 1784:116-132.

Trapp BD, Nishiyama A, Cheng D, Macklin W (1997) Differentiation and death of premyelinating oligodendrocytes in developing rodent brain. J Cell Biol 137:459-468.

Tyler WA, Gangoli N, Gokina P, Kim HA, Covey M, Levison SW, Wood TL (2009) Activation of the mammalian target of rapamycin (mTOR) is essential for oligodendrocyte differentiation. J Neurosci 29:6367-6378.

Wang SZ, Dulin J, Wu H, Hurlock E, Lee SE, Jansson K, Lu QR (2006) An oligodendrocyte-specific zinc-finger transcription regulator cooperates with Olig2 to promote oligodendrocyte differentiation. Development 133:3389-3398.

Woo SY, Kim DH, Jun CB, Kim YM, Haar EV, Lee SI, Hegg JW, Bandhakavi S, Griffin TJ, Kim DH (2007) PRR5, a novel component of mTOR complex 2, regulates platelet-derived growth factor receptor beta expression and signaling. J Biol Chem 282:25604-25612.

Yang W, Zhang Y, Li Y, Wu Z, Zhu D (2007) Myostatin induces cyclin D1 degradation to cause cell cycle arrest through a phosphatidylinositol 3-kinase/AKT/GSK-3 beta pathway and is antagonized by insulin-like growth factor 1. J Biol Chem 282:3799-3808.

Zemke D, Azhar S, Majid A (2007) The mTOR pathway as a potential target for the development of therapies against neurological disease. Drug News Perspect 20:495-499.

Zeng LH, Xu L, Gutmann DH, Wong M (2008) Rapamycin prevents epilepsy in a mouse model of tuberous sclerosis complex. Ann Neurol 63:444-453.

Zhou Q, Choi G, Anderson DJ (2001) The bHLH transcription factor Olig2 promotes oligodendrocyte differentiation in collaboration with $\mathrm{Nkx} 2.2$. Neuron 31:791-807. 